\title{
Toxicity and biodegradation potential of waste water from industry producing fire protection materials
}

\author{
T. Tišler, M. Cotman \& J. Vrtovšek \\ National Institute of Chemistry, Ljubljana, Slovenia
}

\begin{abstract}
Effluents may contain hazardous chemicals, which could have adverse effects on aquatic ecosystems. Important intrinsic properties are toxicity and biodegradability of effluents and they should be assessed in order to protect the aquatic environment. Microorganisms of activated sludge are responsible for biological waste water treatment. The lack of treatment effectiveness could, in case of unexpected toxic influents to waste water treatment plants, lead to a discharge of toxic and undegradable effluents into receiving streams. The assessment of potential adverse effects of influents entering the waste water treatment plant is for this reason necessary. The aim of the study was to predict a suitability of discharging the industrial waste water into waste water treatment plants based on the assessment of waste water toxicity and biodegradability. The waste water sample, originating from the industry producing fire protection materials, was highly polluted with organic substances. At first, the acute toxicity of the investigated sample was determined using activated sludge measuring oxygen consumption rates. It was found that the waste water sample was acutely toxic to microorganisms. Ready biodegradability of waste water was determined in a closed respirometer by measuring oxygen consumption. As diluted samples of the waste water were not readily biodegradable inherent biodegradability of the waste water sample was evaluated using the ZahnWellens test. It was found that diluted samples were inherently biodegradable probably due to the fact that higher concentration of microorganisms of activated sludge was added. It can be concluded that the tested waste water could be discharged into the sewerage system on the condition that a dilution of the tested waste water in the municipal waste water treatment plant would be at least 1:20. Keywords: activated sludge, industrial waste water, inherent biodegradability, oxygen consumption, ready biodegradability, toxicity, Zahn-Wellens test, waste water treatment plant.
\end{abstract}




\section{Introduction}

Aquatic ecosystem is vulnerable to pollution as many chemicals are released into the aquatic environment during their production and final use. One of the most important aspects of environmental protection is biodegradability of chemicals as a biodegradable substance is anticipated to cause less ecological problems than a persistent one. Major pollution is contributed to by effluents as they are important sources of chemicals entering aquatic ecosystems. Therefore, efficient treatment systems are needed for reduction of pollution and biological waste water treatment plants (WWTP) using activated sludge are the most important facilities for cleaning effluents. The WWTP system is based on the biodegradation processes of organic substances similar to that in the aquatic environment [1].

Due to the fact that biodegradation is an important process in WWTP for removing organic substances biodegradability of the inflow of waste water should be predicted before entering the WWTP. Many testing strategies have been described for biodegradability assessment of pure chemicals involving standardised tests initiated or updated by ISO and OECD [2]. However an assessment of waste water biodegradability could be a problem due to unknown composition of waste water leading to analytical limitations [3]. Three groups of tests were defined in order to assess biodegradability of pure chemicals: (1) ready biodegradability test (2) potential (inherent) biodegradability test (3) simulation test. Tests for ready biodegradability assessment i.e. carbon dioxide evolution test, manometric respirometry, closed bottle test indicate if a chemical is degradable without problems under natural conditions. These tests basically distinguish between readily biodegradable chemicals and others. In a case of negative result obtained a test for inherent biodegradability is required. Higher concentration of microorganisms is added to samples for providing optimal conditions for degradation and the Zahn-Wellens test is frequently used for this purpose. Finally, a simulation test is used to provide information about behaviour of substance in specific environmental conditions [4-6].

The aim of our study was to predict biodegradability of industrial waste water originating from the industry producing fire protection materials in the WWTP. At first acute toxicity of the waste water sample was determined using activated sludge to eliminate possible inhibition of biodegradation in further experiments due to waste water toxicity. Ready biodegradability of the waste water sample was determined by measuring the oxygen consumption in a closed respirometer. In the next step, the Zahn-Wellens test was used to assess the inherent biodegradability of the waste water sample. A suitability of discharging the investigated waste water into WWTP was predicted on the results obtained.

\section{Material and methods}

In the waste water sample the $\mathrm{pH}[7], \mathrm{COD}[8]$, and $\mathrm{BOD}_{5}[9]$ were determined.

All experiments on toxicity and biodegradability assessment were conducted in a temperature controlled room at $21 \pm 1^{\circ} \mathrm{C}$. 


\subsection{Acute toxicity of waste water}

The acute toxicity test with activated sludge was performed according to the ISO standard [10] using high concentration of microorganisms $(1500 \mathrm{mg} / \mathrm{L}$ of suspended solids). Microorganisms of activated sludge were obtained from the aeration tank of the laboratory municipal waste water treatment plant and prior testing the sensitivity of microorganims was checked with the reference chemical (3,5-dichlorophenol). Oxygen consumption of the samples was measured with an oxygen electrode (WTW Oximeter, OXI 96) following the biochemical degradation of easy degradable meat extract, peptone, and urea until the oxygen concentration dropped below $1 \mathrm{mg} / \mathrm{L}$. The calculated oxygen consumption rates of different concentrations of waste water were compared to the control without added waste water and the percentages of inhibition were calculated for each waste water concentration. The percentages of inhibition were plotted against corresponding concentrations of waste water on the semi logarithmic paper. The test results were expressed as effective concentrations, which reduced the oxygen consumption by $20 \%, 50 \%$, and $80 \%$ (EC20, EC50, EC 80 values) and were determined using linear regression analysis. The EC20 value was taken as a toxicity threshold.

\subsection{Ready biodegradability}

Aerobic ready biodegradability of the waste water was determined in a closed respirometer (Baromat WTW, BSB - Messgerät, Model 1200) by measuring the oxygen consumption [11]. The final concentration of microorganims was 30 $\mathrm{mg} / \mathrm{L}$ of suspended solids using the same source of activated sludge as in the toxicity test. The oxygen consumption was measured during 28 days in the following samples; the samples containing 3, 4, $5 \mathrm{v} / \mathrm{v} \%$ of the waste water (test medium, corresponding volume of waste water, inoculum), a blank control (test medium, inoculum), a control to check the sensitivity of inoculum (test medium, sodium acetate, inoculum), and an abiotic control (test medium, waste water, $\mathrm{HgCl}_{2}$ solution). Biodegradation curves were plotted as the percentages of biodegradation for each concentration of the waste water versus time. A final level of biodegradation, a lag phase and a degradation time were the parameters used for biodegradability assessment.

\subsection{Inherent biodegradability}

Aerobic inherent biodegradability of the waste water was determined using the Zahn-Wellens test [12]. The same source of microorganisms was used as in the previous experiments with the final concentration of $400 \mathrm{mg} / \mathrm{L}$ of suspended solids. The same samples with continuous homogenisation and aeration were tested as in the ready biodegradation experiment. The elimination of organic matter in the samples was followed by dissolved organic carbon (DOC) measurements (TOC Analyser - 5000A, Shimadzu) during 28 days. The evaluation of biodegradability was carried out in the same manner as in the ready biodegradability assessment. 


\section{Results and discussion}

The $\mathrm{pH}$ of the sample was 10.3 , the waste water was polluted with organic matter; the COD and $\mathrm{BOD}_{5}$ were $3659 \mathrm{mg} / \mathrm{L}$ and $901 \mathrm{mg} / \mathrm{L}$, respectively.

\subsection{Acute toxicity to activated sludge}

A waste water toxicity was determined using the acute toxicity test with activated sludge (Table 1) to eliminate possible inhibition of biodegradation in further experiments.

Table 1: Inhibition of oxygen consumption in different concentrations of waste water.

\begin{tabular}{|c|c|c|}
\hline $\begin{array}{c}\text { Concentration of waste } \\
\text { water (v/v \%) }\end{array}$ & $\begin{array}{c}\text { Oxygen consumption } \\
\text { rates }(\mathrm{mg} / \mathrm{L} . \mathrm{h})\end{array}$ & Inhibition (\%) \\
\hline 0 & 0.493 & $/$ \\
\hline 1 & 0.506 & 5 \\
\hline 3 & 0.468 & 65 \\
\hline 7 & 0.173 & 87 \\
\hline 10 & 0.064 & 97 \\
\hline 20 & 0.015 & 100 \\
\hline 40 & 0.005 & 100 \\
\hline 70 & 0.005 & $/$ \\
\hline Abiotic -40 & 0 & \\
\hline
\end{tabular}

The EC values were calculated from the obtained results (Table 1):

$30 \mathrm{~min} \mathrm{EC} 20=3.7 \mathrm{v} / \mathrm{v} \%$

$30 \mathrm{~min} \mathrm{EC} 50=5.9 \mathrm{v} / \mathrm{v} \%$

$30 \mathrm{~min} \mathrm{EC} 80=8.9 \mathrm{v} / \mathrm{v} \%$

The waste water sample was highly toxic to microorganisms of activated sludge. The sample of $5.9 \mathrm{v} / \mathrm{v} \%$ of waste water inhibited the oxygen consumption by $50 \%$ and a toxicity threshold was found in the sample containing $3.7 \mathrm{v} / \mathrm{v} \%$ of waste water.

\subsection{Ready biodegradability}

In regard to the obtained toxicity, the concentrations of waste water sample used in biodegradability tests were between 3 and $5 \mathrm{v} / \mathrm{v} \%$ of the waste water sample. The results obtained in the ready biodegradability test are given in Fig. 1.

In all tested samples a lag phase (2-4 days) was observed; the highest and the lowest final levels of biodegradation were found in the samples containing $3 \mathrm{v} / \mathrm{v} \%(47 \%)$ and $5 \mathrm{v} / \mathrm{v} \%(31 \%)$ of the waste water, respectively. The nontoxic sample containing $3 \mathrm{v} / \mathrm{v} \%$ of the waste water was not readily 
biodegradable according to the recommendations for the ready biodegradability classification of pure chemicals as the "pass level" of biodegradation in the $\mathrm{O}_{2}$ and $\mathrm{CO}_{2}$ tests was not achieved [6].

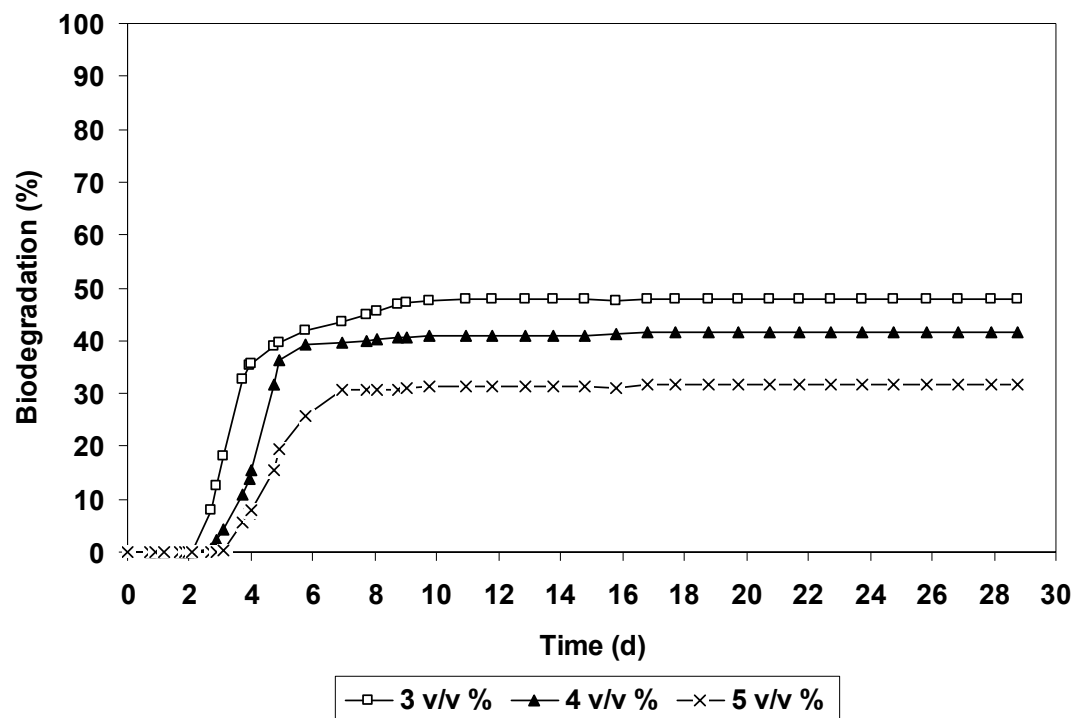

Figure 1: Biodegradation curves of the samples containing 3, 4, and $5 \mathrm{v} / \mathrm{v} \%$ of waste water - closed respirometer.

\subsection{Inherent biodegradation}

The results obtained in a test for inherent biodegradability assessment are given in Fig. 2.

In the Zahn - Wellens test biodegradation started immediately without a lag phase and the biodegradation was completed in 12 days. The same final levels of biodegradation (about 80\%) were determined in the samples containing 3 and $5 \mathrm{v} / \mathrm{v} \%$ of the waste water (Fig. 2). We concluded that both samples were inherently biodegradable as biodegradation was higher than $70 \%$ [2]. Better biodegradability of the tested sample was probably due to higher concentration of microorganisms added in the Zahn - Wellens test.

The final levels of biodegradation obtained in the $\mathrm{O}_{2}$ test $(31 \%-47 \%)$ and the Zahn-Wellens test $(80 \%)$ were higher than the $\mathrm{BOD}_{5} / \mathrm{COD}$ ratio $(25 \%)$. The reasons are probably more favourable conditions in biodegradability tests such as duration of experiments and amount of added microorganisms. 


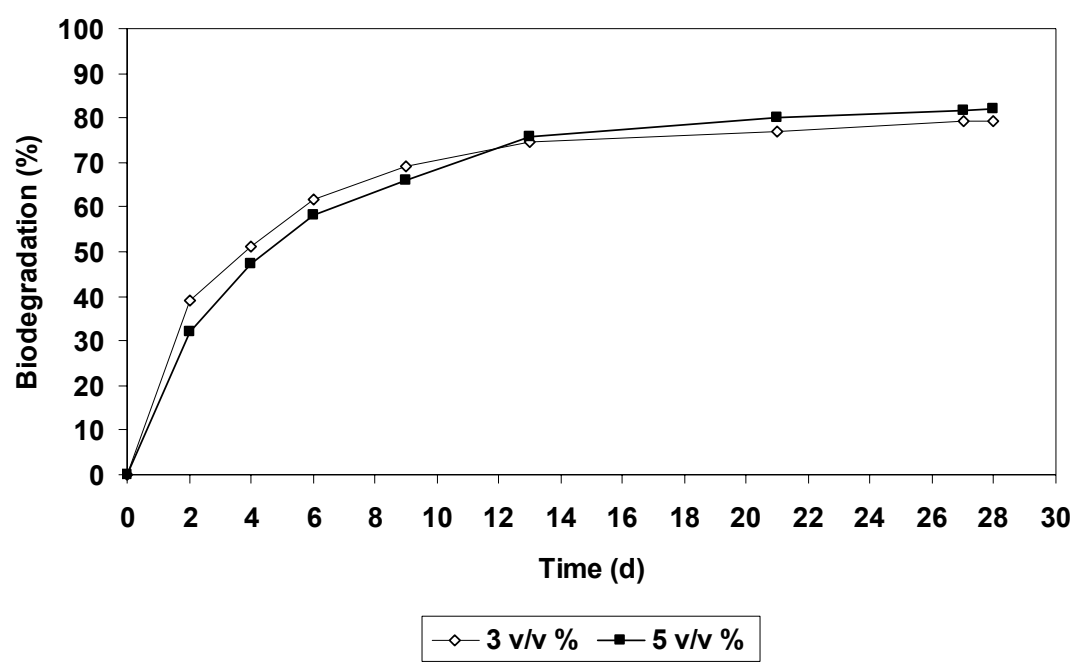

Figure 2: Biodegradation curves of the samples containing 3 and $5 \mathrm{v} / \mathrm{v} \%$ of waste water - Zahn - Wellens test.

\section{Conclusions}

The waste water sample, obtained from the industry producing fire protection materials, was acutely toxic to activated sludge; a toxicity threshold was found even at $3.7 \mathrm{v} / \mathrm{v} \%$. All tested samples of the waste water were not readily biodegradable. However it was found that the investigated sample were biodegradable in the Zahn - Wellens test in the samples containing 3 and $5 \mathrm{v} / \mathrm{v} \%$ of the waste water. The experimental conditions in the Zahn-Wellens test are closer to a WWTP system than an oxygen consumption measurements in a closed respirometer. Based on the results obtained we can conclude that the investigated waste water could be treated in the municipal waste water treatment plant on condition that the inflow of this waste water will not exceed $5 \mathrm{v} / \mathrm{v} \%$ of total volume of waste waters. It means that a ratio of the investigated waste water and total inflow in the WWTP should never be less than 1:20.

\section{References}

[1] Pagga, U., Testing biodegradability with standardized methods. Chemosphere, 35(12), pp. 2953-2972, 1997.

[2] Painter, H.A., Detailed review paper on biodegradability testing, OECD Guidelines for the testing of chemicals, OECD Paris, 1995.

[3] Nyholm, N., Biodegradability characterisation of mixtures of chemical contaminants in waste water - The utility of biotests. Wat Sci Tech, 33(6), pp. 195-206, 1996. 
[4] Žgajnar-Gotvajn, A., Zagorc-Končan, J., Whole effluent and single substances approach: A tool for hazardous waste water management. Wat Sci Tech, 37(8), pp. 219-227, 1998.

[5] Lapertot, M.E., Pulgarin, C., Biodegradability assessment of several priority hazardous substances: Choice, application and relevance regarding toxicity and bacterial activity. Chemosphere, in press.

[6] Struijs, J., van den Berg, R., Standardized biodegradability tests: Extrapolation to aerobic environments. Wat Res, 29(1), pp. 255-262, 1995.

[7] International Organisation for Standardization, International Standard ISO 10523. Determination of $\mathrm{pH}$. Geneve, 1996.

[8] International Organisation for Standardization, International Standard ISO 6060. Water Quality - Determination of chemical oxygen demand. Geneve, 1996.

[9] International Organisation for Standardization, International Standard ISO 5815 - 1. Water Quality - Determination of biochemical oxygen demand after $\mathrm{n}$ days (BODn), Dilution and seeding method with allylthiourea addition. Geneva, 2003.

[10] International Organisation for Standardization, International Standard ISO 8192: Water Quality - Test for inhibition of oxygen consumption by activated sludge. Geneve, 1986.

[11] International Organisation for Standardization, International Standard ISO 9408: Water Quality - Evaluation of ultimate aerobic biodegradability of organic compounds in aqueous medium by determination of oxygen demand in a closed respirometer. Geneve, 1999.

[12] International Organisation for Standardization, International Standard ISO 9888: Water Quality - Evaluation of the aerobic biodegradability of organic compounds in an aqueous medium - Static test (Zahn-Wellens method). Geneve, 1999. 